\title{
The Study of the Effect of a 16-Week Program of Resistance-Aerobic Training on BDNF, Hba1c, Pain, and Michigan Neuropathy Score Among Type 2 Diabetic Patients with Peripheral Neuropathy
}

Tayebe Amiri Parsa ${ }^{1^{*}}$, Seyyed Reza Attarzadeh Hosseini ${ }^{2}$, Nahid Bije ${ }^{2}$ and Mohammad Reza Hamedi $\mathrm{Nia}^{3}$

${ }^{1}$ Biochemistry and Sport Metabolism, Ferdowsi University of Mashhad, Mashhad, IR Iran

${ }^{2}$ Sport Physiology, Ferdowsi University of Mashhad, Mashhad, IR Iran

${ }^{3}$ Sport Physiology, Hakim SabzevariUniversity, Sabzevar, IR Iran

"Corresponding author: Tayebe Amiri Parsa, Biochemistry and Sport Metabolism, Ferdowsi University of Mashhad, Iran, Tel: +989155717247; E-mail: amiritayebe@yahoo.com

Received date: September 16, 2018; Accepted date: October 30, 2018; Published date: November 05, 2018

Copyright: (C) 2018 Parsa TA, et al. This is an open-access article distributed under the terms of the Creative Commons Attribution License, which permits unrestricted use, distribution, and reproduction in any medium, provided the original author and source are credited.

\section{Abstract}

Objectives: Very few data on the role of exercise training on diabetic peripheral neuropathy have been reported. The present study was aimed at investigating the effect of resistance- aerobic training for 16 weeks on Brain-derived Neurotropicfactor (BDNF), Hemoglobin A1c (HbA1c), pain, and Michigan Neuropathy score among type-2 diabetic patients with peripheral neuropathy.

Materials and methods: A total of 24 diabetic patients with peripheral neuropathy were randomly assigned to the control (subject:11) and the experimental group (subject:13). The subjects in the experimental group were required to follow a combined of resistance-aerobic training 3 sessions a week for 16 consecutive weeks. Blood samples were taken from all of the participants once before the start of the study, and at the end of the first, second, third, and fourth months. The pain felt by the subjects was measured with the Visual Analogue Scale concurrent with the blood sampling procedure.

Findings: The results showed that resistance-aerobic training had no statistically significant effect on the BDNF, Glucose, and $\mathrm{HbA} 1 \mathrm{c}$ indexes of the experimental group at $\mathrm{P}>0.05$. However, the level of pain, lower body limb strength, and Michigan Neuropathy score of the experimental group subjects showed a meaningful improvement compared to those of the subjects in the control group.

Conclusion: Although the BDNF serum level did not show any meaningful reduction after resistance-aerobic training, the pain felt, strength, and Michigan neuropathy score improved. It seems highly likely that following resistance-aerobic training can prevent the increase of glucose level in the blood and the reduction of BDNF level in the blood.

Keywords: BDNF; Diabetic neuropathies; Exercise; Hemoglobin A1c; Pain

\section{Introduction}

Diabetes has been considered as one of the most alarming complications faced by the health care systems throughout the world in the twentieth century. It is widely believed that the widespread changes in the environment, life style, and behavioral patterns have led to obesity and diabetes which almost always accompany obesity, often referred to by the coined term diabesity encompassing both. Diabetes is associated with some chronic side effects, the most common of which is diabetic neuropathy. It is estimated that nearly $50 \%$ of diabetic patients suffer from peripheral neuropathy which is directly associated with poor diabetes control measures, often leading to therapeutic amputations [1]. Patients suffering from neuropathic pain usually complain about chronic consistent pain, burning, prickling and tingling caused by gentle touch [2]. Pharmacological control and management of neuropathic pain poses its own clinical challenges in that despite the diverse medications available for the control of neuropathic pain, they are associated with some side effects [3]. However, non-pharmacological approaches such as electrical stimulation of peripheral nerves, acupuncture, sonography, and regular exercise have been extensively effective in the treatment of neuropathic pain [4]. In addition, these approaches are beneficial because they allow the long-term effects of type- 2 diabetes and the additional costs related to multiple medications prescribed, and the negative side effects associated with drug combinations to be avoided [5].

Although the effect mechanism of exercise on neuropathic pain is not fully understood, there is growing evidence indicating that regular exercise is effective in improving the dysfunction caused by diabetes and neuropathic pain [6]. Theoretically, the physical activity is likely reduce the development of diabetes in diabetic neuropathy through reducing and glucose level [7] and inflammation [8]. One of the mechanism involved is the mechanism related to the effect of exercise on the level of BDNF.

BDNF is one of the members of neurotrophin family considered important for the constant neural functioning, providing support for the survival of neurons in the peripheral and central nervous system. 
Citation: Parsa TA, Hosseini SRA, Bije N, Nia MRH (2018) The Study of the Effect of a 16-Week Program of Resistance-Aerobic Training on BDNF, Hba1c, Pain, and Michigan Neuropathy Score Among Type 2 Diabetic Patients with Peripheral Neuropathy. J Diabetes Metab 9: 811. doi:10.4172/2155-6156.1000811

Page 2 of 8

Neurotrophins function as support factors on nervous system, preventing damage to neurons in diabetes [9]. Alexis et al. investigated whether the increased level of neurotrophins induced by physical activity could improve the functioning and structure of neurons in diabetes [10]. The results obtained in their study revealed an increased level of BDNF and a reduction of the destructive effect of diabetes on the plasticity of hippocampus neurons.

With the same token, the results of the study performed by Kluding et al., showed that a ten-week program of aerobic and resistance training in patients with neurotrophic pain led to a decreased level of pain and the neuropathic symptoms associated with neurotrophic pain [11]. However, Swift et al., found that a program of nine months of aerobic, resistance and combined training led to no significant changes in the BDNF level among diabetic female patients [12].

The American Diabetes Association and The American College of Sports Medicine confirmed that the rehabilitation program for diabetic patients should involve a combination of aerobic and resistance training so that the therapeutic benefits of both programs can be obtained. It has been demonstrated that a combination of resistance and aerobic exercise program is effective in controlling blood glucose level and insulin activity, and in reducing the risk factors for cardiovascular diseases [13].

The majority of studies done so far on diabetic individuals either have focused on making comparisons between the potential effects of aerobic exercises and those of resistance exercises, or have dealt with the potential effects of one type of exercise such as aerobic exercise $[14,15]$, or have used animals as their subjects $[16,17]$. In addition, in some of the studies done previously, although the guidelines suggested by ACSM were generally followed, the efficient volume of the program which could have highest effect on the indexes associated with the disease was not dealt with. Given the widespread occurrence of diabetes, the costs and side effects associated with it, the destructive effect of diabetes on the life quality of the patients, and given that the studies conducted so far have produced contradictory results about the effect of exercise programs on reducing chronic and sever pain level felt, the present study is aimed at investigating the potential effect of a combined exercise program (resistance-aerobic) on BDNF, pain level, and Michigan score among type -2 diabetic patients with peripheral neuropathy.

\section{Research Method}

The population of the study consisted of all diabetic women suffering from peripheral neuropathy living in Sabzevar. From among these female patients, a sample of 24 Postmenopausal female patients between 45 to 65 years old were selected. In the selection of the subjects for the study, the following inclusion criteria were employed: being between 45 to 65 years old, having no amputations, suffering no sole lesions, having no intense retinopathy, not suffering nephropathy, not going under dialysis, not having non-diabetic neuropathy, not having a history of frequent ankle sprains during the last year, and not following a regular exercise program in the last 6 months. All the patients coming to the center were checked for neuropathy by a specialist. In the present study, a score of 2 or higher obtained on the Michigan Neuropathy Questionnaire was considered to be indicative of the presence of neuropathy. Finally all the subjects were interviewed and were informed of the purpose of the study. From among the patients, samples of 24 patients who were able to go through the resistance exercises with weights, and could do aerobic exercises were selected for the inclusion in the final study. Before the start of the study, all the subjected showed their formal written consent to participate in the study. The subjects were then randomly assigned to the control (subject:11) and experimental group (subject:13). Three subjects from the experimental group and 4 ones from the control grouped dropped out of the study. Moreover, some exclusion criteria were used in the study such as a subject's inability to perform the activities or the existence of pain in the chest. The experimental group subjects were gone under electrocardiogram and echocardiogram tests before the study. Finally, before the start of the training program, a blood sample of $3 \mathrm{~mm}$ was taken from each subject in experimental and control group at $8 \mathrm{AM}$ after 10 to 12 hours of fasting and was sent to lab for biochemical tests (such as BDNF, glucose and $\mathrm{HbA1C}$ measurements).

The pain level felt and the blood tests were performed for the subjects after the fourth, eighth, twelfth, and sixteenth weeks following the same procedures employed in the pretest stage. Moreover, the cardiovascular system health and the maximum strength of the lower body were evaluated in three stages: pre-study, two months and four months after the completion of the study. In addition, the neuropathy Michigan questionnaire was administered before the study and after 16 weeks following the completion of the study while the subjects were interviewed and clinically examined so that their neuropathic pain level can be determined before and after the study. In the course of the study, all the subjects continued taking the same glucose inhibiters (such as Glibenclamide and metformin) they took before the study to lower the glucose level in their blood.

\section{The sample size estimation}

The following formula with a power of $\mathrm{a}=80$ was implemented to determine the number of the subjects in the sample. It was determined that the sample should include some 20 subjects. However, to be on the safe side, the final number of the subjects in the sample was decided to be 24 . However, from the experimental group some 3 subjects were omitted due to chest pain during the training (a subjects) and the death of close relatives ( 2 subjects). In the control group, 4 subjects were omitted due to accident (1 subjects) and personal reasons (3 subjects).

\section{Criteria for neuropathy identification}

The Michigan Neuropathy Questionnaire was employed to identify peripheral neuropathy among the subjects [18].

\section{Pain estimation}

The Visual Analogue Scale, which is the most widely used pain measurement instrument in the world, was implemented to measure the amount of desk pained felt by the patients.

\section{Maximum strength estimation (1RM)}

The maximum strength of the lower body limbs (Leg press test) is determined using the following formula [19].

$\% 1 \mathrm{RM}=[100-(2 / 5 \times$ Repetition $)]$

\section{Method of BDNF, glucose and HbA1C measurements}

Serum BDNF was assayed using a Chemikine BDNF sandwich enzyme-linked immunosorbent assay (ELISA) kit. HbAlc was 
Citation: Parsa TA, Hosseini SRA, Bije N, Nia MRH (2018) The Study of the Effect of a 16-Week Program of Resistance-Aerobic Training on BDNF, Hba1c, Pain, and Michigan Neuropathy Score Among Type 2 Diabetic Patients with Peripheral Neuropathy. J Diabetes Metab 9: 811. doi:10.4172/2155-6156.1000811

Page 3 of 8

measured by turbidimetric inhibition immunoassay (Roche, Basel, Switzerland) and to measure blood glucose, the b-glucose test (vakpar, nosaka, and Japan) was used. The ELISA kit was used to determine the insulin levels of the commercial kit (ERG, UK).

\section{Training protocol}

Every training session started with fifteen minutes of warm-up exercises followed by resistance exercises. The resistance exercises included: Machine chest press, Machine Lat pull -down, Dumbbell Bicep, Dumbbell triceps, Machine Leg Extention, and Machine Prone Leg Curl. Moreover, the subjects performed Sit- up and Push-up. The load were chosen so that the subjects could perform each movement 8 to 12 times fin each station. The workout movements were performed in two sets in the first four weeks. From the fifth to the eighth week, however, the movements were performed in three sets. From the ninth week until the end of the study, they were performed in 4 sets. Moreover, there were 6 stations from the first to the seventh week. During the eighth and ninth weeks, the subjects performed the movements in 7 stations in each session. Then, they had to perform the movements in 8 different stations until the end of the study. The subjects were asked to repeat the movements 8 to 12 times, with a minute of rest between each sets, and two minutes of rest between stations. After performing resistance exercises, the subjects started endurance exercises after a short rest (3-5 minute rest). The endurance exercises consisted of aerobic rhythmic exercises and running in intervals of 3 minutes followed by 30 seconds of rest. The intensity of the exercises started with $50 \%$ if heart rate reserve in the first week until it reached $75 \%$ of heart rate reserve. Similarly, the number of repetitions grew from 5 during the first week, 10 in the thirteenth and fourteenth weeks, 11 in the fifteenth, to 12 repetitions in the sixteenth week. At the end of each training session, the subjects were asked to perform some cool-down exercises for 5 to 10 minutes. The exercises were performed three sessions a week at a gym suitable for the subjects in terms of light, temperature, and moisture.

\section{Statistical Tests}

The obtained data were subjected to descriptive statistical analyses including measures of central tendency and standard deviation. The Shapiro-Wilk test was implemented to check the normality of the distribution of data gathered. Moreover, the Levene's test was performed on the data to examine the homogeneity of the variance in the experimental and control groups. Moreover, a univariate ANOVA and a repeated measure ANOVA were conducted to check the intergroup differences and within group differences, respectively. In addition, given the lack of homogeneity of variances of the oral interview of the Michigan Screening Questionnaire, an independent ttest was used to check the between group differences of the experimental and the control group. All the statistical analyses were performed using SPSS statistical package (version 16), using a significance level of $\mathrm{p}<0.05$.

\section{Results}

The complete results are in Tables 1-5.

\begin{tabular}{|l|l|c|c|c|c|}
\hline \multicolumn{2}{|c|}{ Parameter } & Age & Weight & Height & BMI \\
\cline { 3 - 6 } & & Mean (SD) & Mean (SD) & Mean (SD) & Mean (SD) \\
\hline \multirow{3}{*}{ Pre test } & Experimental & $4.06 \pm 56.4$ & $11.41 \pm 73.25$ & $0.03 \pm 1.55$ & $4.06 \pm 30.28$ \\
\cline { 2 - 6 } & Control & $3.88 \pm 58.75$ & $11.23 \pm 68.56$ & $0.01 \pm 1.59$ & $4.45 \pm 26.95$ \\
\hline \multirow{3}{*}{ Post test } & Experimental & $4.06 \pm 56.4$ & $11.72 \pm 72.23$ & $0.03 \pm 1.55$ & $4.02 \pm 29.83$ \\
\cline { 2 - 6 } & Control & $3.88 \pm 58.75$ & $10.58 \pm 71.11$ & $0.01 \pm 1.59$ & $4.27 \pm 27.96$ \\
\hline
\end{tabular}

Table 1: Demographic data at pre-test and post-test in two groups respectively.

\begin{tabular}{|c|c|c|c|c|}
\hline \multicolumn{2}{|c|}{ Leg Press } & Mean (SD) & Significant difference between groups & $\mathbf{F}$ \\
\hline \multirow{2}{*}{ Pretest } & Experimental & $69.35 \pm 48.04$ & \multirow{2}{*}{0.28} & \multirow{2}{*}{1.2} \\
\hline & Control & $50.53 \pm 18.84$ & & \\
\hline \multirow{2}{*}{ Second Month } & Experimental & $93.2 \pm 64.94$ & \multirow{2}{*}{0.03} & \multirow{2}{*}{5.3} \\
\hline & Control & $42.33 \pm 12.72$ & & \\
\hline \multirow{2}{*}{ Fourth Month } & Experimental & $131.95 \pm 112.16$ & \multirow{2}{*}{0.03} & \multirow{2}{*}{5} \\
\hline & Control & $47.05 \pm 16.95$ & & \\
\hline \multirow{2}{*}{ Significant Difference Within Group } & $P$ value & \multicolumn{3}{|c|}{0.02} \\
\hline & $\mathrm{F}$ & 6.28 & & \\
\hline
\end{tabular}

Table 2: Depicting the change in mean and standard deviation for parameter of leg press at pre-test, second, and fourth month in two groups respectively. 
Citation: Parsa TA, Hosseini SRA, Bije N, Nia MRH (2018) The Study of the Effect of a 16-Week Program of Resistance-Aerobic Training on BDNF, Hba1c, Pain, and Michigan Neuropathy Score Among Type 2 Diabetic Patients with Peripheral Neuropathy. J Diabetes Metab 9: 811. doi:10.4172/2155-6156.1000811

Page 4 of 8

\begin{tabular}{|c|c|c|c|c|c|c|c|c|c|}
\hline & & BDNF & & Pain & & Glucose & & HbA1C & \\
\hline Parameter & & Mann (CD) & $\begin{array}{l}\text { Significant } \\
\text { difference }\end{array}$ & Man (cD) & $\begin{array}{l}\text { Significant } \\
\text { difference }\end{array}$ & & $\begin{array}{l}\text { Significant } \\
\text { difference }\end{array}$ & Mean & $\begin{array}{l}\text { Significant } \\
\text { difference }\end{array}$ \\
\hline Pretest & Experimental & $3.13 \pm 0.42$ & 0.45 & $5.72 \pm 5$ & 0.77 & $134 \pm 22.96$ & 0.94 & $\begin{array}{c}9.27 \pm \\
1.42\end{array}$ & 0.09 \\
\hline & Control & $3.53 \pm 0.58$ & & $5 \pm 3.4$ & & $179.37 \pm 71.9$ & & $8.7 \pm 1.49$ & \\
\hline & Experimental & $3.36 \pm 0.18$ & & $4.18 \pm 4$ & & $\begin{array}{c}137.66 \pm \\
32.87\end{array}$ & & $\begin{array}{c}9.55 \pm \\
1.78\end{array}$ & \\
\hline & Control & $3.66 \pm 0.66$ & & $7 \pm 3.56$ & & $\begin{array}{c}200.75 \pm \\
63.63\end{array}$ & & $9.1 \pm 1.73$ & \\
\hline & Experimental & $3.29 \pm 0.19$ & & $2.8 \pm 3$ & & $138.66 \pm 31.4$ & & $9.32 \pm 1.6$ & \\
\hline & Control & $3.47 \pm 0.56$ & & $7 \pm 4.05$ & & $207 \pm 77$ & & $8.9 \pm 2.03$ & \\
\hline Third Month & Experimental & $3.4 \pm 0.28$ & 0.38 & $2.5 \pm 3$ & 0.02 & $129.11 \pm 25.43$ & 0.86 & $\begin{array}{c}9.23 \pm \\
1.71\end{array}$ & 0.6 \\
\hline & Control & $3.59 \pm 0.61$ & & $7.5 \pm 3.88$ & & $154.5 \pm 59.01$ & & $9.02 \pm 1.9$ & \\
\hline & Experimental & $3.41 \pm 0.33$ & & $2.25 \pm 3$ & & $139 \pm 20.54$ & & $8.49 \pm 1.5$ & \\
\hline Fourth Month & Control & $3.48 \pm 0.56$ & 0.79 & $6.5 \pm 3.88$ & 0.01 & $156 \pm 46.83$ & 0.49 & $\begin{array}{c}8.27 \pm \\
1.67\end{array}$ & 0.5 \\
\hline Significant & $P$ value & & 0.62 & & 0.42 & & 18 & & 0.01 \\
\hline Within Group & $\mathrm{F}$ & 0.66 & & & & & & & \\
\hline
\end{tabular}

Table 3: Depictingthe change in mean and standard deviation for parameters of BDNF, pain, glucose, HbA1C atpretest, first, second, third and fourth month in two groups respectively.

\begin{tabular}{|l|l|c|c|c|}
\hline \multicolumn{2}{|c|}{ Michigan Score ( Interview Part) } & Mean (SD) & $\begin{array}{c}\text { Significant } \\
\text { difference } \\
\text { between } \\
\text { groups }\end{array}$ & F \\
\hline \multirow{2}{*}{ Pretest } & Experimental & $4.81 \pm 2.04$ & \multirow{2}{*}{0.42} & \multirow{2}{*}{4.5} \\
\cline { 2 - 3 } & Control & $6 \pm 3.87$ & \multirow{2}{*}{0.00} & \multirow{2}{*}{0.00} \\
\hline \multirow{2}{*}{ Post Test } & Experimental & $1.81 \pm 1.32$ & \\
\cline { 2 - 3 } & Control & $6.33 \pm 3.39$ & \\
\hline \multirow{2}{*}{$\begin{array}{l}\text { Significant Difference } \\
\text { Within Group }\end{array}$} & P value & F & 10.56 & \\
\cline { 2 - 3 } & & & \multicolumn{2}{|c|}{} \\
\hline
\end{tabular}

Table 4: Depicting the change in mean and standard deviation for parameter of michiganscore ( interviewpart) at pretest and post test in two groups respectively.

The results obtained revealed that the combined program of resistance-aerobic exercise for 4 months had no statistically significant effect on BDNF, glucose, and HbAlc indexes of the experimental group at $\mathrm{P}>0.05$. However, the level of pain, lower body limb strength, and Michigan Neuropathy score of the experimental group subjects showed a meaningful improvement compared to those of the subjects in the control group. Tables 1-5 summarize the results.

\begin{tabular}{|l|l|c|c|c|}
\hline \multicolumn{2}{|c|}{ Michigan Score (Clinical Part) } & Mean (SD) & $\begin{array}{c}\text { Significant } \\
\text { difference } \\
\text { between } \\
\text { groups }\end{array}$ & F \\
\hline \multirow{2}{*}{ Pretest } & Experimental & $5.05 \pm 1.37$ & \multirow{2}{*}{0.31} & \multirow{2}{*}{1.1} \\
\cline { 2 - 3 } & Control & $5.37 \pm 1.12$ & \multirow{2}{*}{0.02} & \multirow{2}{*}{0.7} \\
\hline \multirow{2}{*}{ Post test } & Experimental & $3.44 \pm 1.58$ & \\
\cline { 2 - 3 } & Control & $5.37 \pm 1.45$ & \\
\hline $\begin{array}{l}\text { Significant } \\
\text { Difference Within } \\
\text { Group }\end{array}$ & P value & & & \\
\cline { 2 - 3 } & F & 20.9 & \\
\hline
\end{tabular}

Table 5: Depicting the change in mean and standard deviation for parameter of michiganscore (clinicalpart) at Pretest and post test in two groups respectively.

\section{Discussion}

In general, the results obtained in the present study showed that although a 4 month combined program of resistance-aerobic training helped improve the pain level, the strength of lower limbs, and the Michigan Neuropathy score of the patients with peripheral neuropathy as measured by the oral interview and clinical examination parts of Michigan Neuropathy questionnaire, it did not seem to have any statistically significant influence on BDNF, glucose, glycated 
Citation: Parsa TA, Hosseini SRA, Bije N, Nia MRH (2018) The Study of the Effect of a 16-Week Program of Resistance-Aerobic Training on BDNF, Hba1c, Pain, and Michigan Neuropathy Score Among Type 2 Diabetic Patients with Peripheral Neuropathy. J Diabetes Metab 9: 811. doi: $10.4172 / 2155-6156.1000811$

Page 5 of 8

hemoglobin, and the fat percent of the patients. The findings obtained in the present study are in line with those obtained by Hvid et al. 2017 [20]. They showed that implementation of a 12 week program of strength exercises did not lead to any change in the basic level of BDNF in elderly patients with movement limitations, concluding that BDNF cannot be considered as the primary mechanical factor in modifying neuroplasticity among these people.

With the same token, Forti et al. (2012) observed that the 12-weeklong program of progressive resistance exercises did not bring about any statistically significant change in serum BDNF level in old people, concluding that this finding can be accounted for by fact that the BDNF response is short-lived in such a way that it is observable immediately after each training session but washes out by the time the blood samples are taken [21].

Similarly, in their study, Yarrow et al. (2010) showed that the resistance training program resulted in a dramatic but transient change in BDNF. They reasoned that regular resistance exercises can improve this response, but it does not have any influence on rest BDNF level [22]. This conclusion is confirmed by the results obtained by Castellano and White (2008) which showed that an eight-week program of aerobic exercises led to a transient change in the rest BDNF level only during the first 4 weeks of the program [23].

However, there are a number of studies which provided results contrary to those obtained in the present study. For example, Kim et al. (2014) observed that an aerobic- resistance program of 12 weeks was associated with a significant increase in both BDNF level and muscle strength in Schizophrenic patients [24]. In contrast, in the study conducted by Almeida et al. (2015), physical activity led to a decrease in BDNF expression level, and reduced the positive regulating effect of NGF in Dorsal Root Ganglion [25].

In the present study, the implementation of a resistance-aerobic combined program for 16 weeks did not led to any statistically significant increase in BDNF level of the patients. In this study, every necessary measure was taken to run the training program according to the guidelines and instructions provided by ACSM so that the training program could have maximal effect on BDNF. However, the results of the present study indicated that physical training programs should be followed for more than 16 weeks if they are to be of any positive influence for diabetic patients suffering from neuropathy. Moreover, the studies conducted so far have revealed that BDNF can be produced in skeletal muscles but it cannot move into the blood circulation. Thus, the lion's share of the BDNF available in the blood is for (produced by) the brain [26]. Therefore, the fact that in the present study, the training program was not significantly in increasing the BDNF level can be partially accounted for by this simple fact. Conversely, the obtained results in the present study can be explained by the short-lived response of BDNF to physical activity, which increases immediately after each training session but washes out by the time samples are taken, as Forti et al. (2014) claimed [20].

The results obtained in the majority of the studies dealing with the potential effect of regular physical activities on the serum BDNF level did not revealed any significant obvious effect on the rest BDNF index [20,27-29]. In the same way, the results of a review study [30] showed that there is no empirically supported fixed protocol for the type and intensity of the exercises effective in increasing BDNF level. It can be concluded that there is no agreement and certainty about the response of Blood BDNF level to physical training programs. Thus, there is a need for more studies on patients and elderly people in this regard [31].

In the present study, the diabetic patients with peripheral neuropathy followed a combined training program regularly for a period of 4 months. However, the glucose levels of the patients did not show any statistically significant change from the first to the fourth month. Aerobic exercises are effective in enhancing the insulin level in all fibers without increasing the fibers while resistance exercises are believed to improve the rate of glucose absorption as the size of the muscle fibers increase [32]. In the present study, a combined training program was implemented so that the potential beneficial effects of both aerobic and resistance exercises could be enjoyed in preventing the increase of glucose level in the blood of the patients.

However, the findings of a few studies revealed a statistically significant decrease in HbA1C. In their study, Eterman et al. (2010) focused on the possible effect of a 12-week program of aerobicresistance training in patients with diabetic feet, who also suffered other diabetic complications. The results of their study showed an improvement in the muscle strength and also a decrease of 8.2 percent in the $\mathrm{HbA1C}$ in the patients. The difference between the findings of Otterman et al., study and those of the present study can be partly due to the fact that in the present study a similar training program was followed for all the peripheral neuropathic patients who showed no other diabetic complications while in Otterman et al. study, the patients received individualized aerobic/strength training programs based on the unique complications they showed and also the objectives set for each patient based on his daily physical performance. Moreover, in the present study sex was controlled, with the subjects being all from one sex (female) while in Otterman et al. study, the participants were of both sexes. In another study, Arora et (2009), patients with type 2 diabetes received a combined program of aerobic-resistance training for 8 consecutive weeks. The results showed a significant improvement in serum $\mathrm{A} 1 \mathrm{C}$ which the researchers believed can be accounted for by the fact that the patients did not follow a regular training program [33]. In their study, the patients had an average age of 53.88.8. While in the present study, the patients were 5 years older on average, 58 years of age. The lack of improvement in the serum A1C of the patients in the present study can be accounted for by the fact that they were comparatively older and were suffering from peripheral neuropathy. Moreover, the patients in the present study were females while in the study conducted by Arora et al., the participants were from both sexes.

Moreover, the results of the previous analyses showed that the $\mathrm{HbAlc}$ level is meaningfully correlated with the amputation of the lower limbs; an increase of one percent in HbAlc level is associated with a 1.3 times higher risk of amputation [34]. Although the HbAlc level did not showed any significant increase during the four months of the present study, the lack of increase in HbAlc level can be of great clinical importance, indicating that following a combined training program can be effective in improving the patients. However, the participants of the present study had been suffering from diabetes for an average period of 12.5 years. As the length of the patient's history of diabetes increases, they build up more resistance to insulin, indicating if patients follow training programs for longer periods of time than that used in the present study, the training program is more likely to have a beneficial impact on the indexes of the patients. Additionally, following physical activity programs can have a faster and more tangible effect in improving the blood glucose level for younger individuals compared to old people (over 55 years old). Therefore, it can be concluded that for diabetic patients with an average age of 58 
and an average history of 12.5 , physical training programs should be followed for periods of more than 4 months if they are to be effective in improving the HbA1c level in any significant way.

Another important factor is the medication taken by the participants of the present study. The dose of medication taken by the participants in both groups were examined before the start of the study, two months after the start of the study, and also after the fourth month. The results of the analyses showed that the glucose inhibiting medication taken by the participants in the control group showed an increase while that of the experimental group showed a decreasing trend. In addition, one of the subjects in the control group was forced to take insulin during the last month of the study in order to control her blood glucose level. The decrease in the glucose inhibiting medication taken in the experimental group and the comparative increase in medication taken observed in the control group provide and explanation for why the implementation of the training program for four months was observed to have no statistically significant influence on the $\mathrm{HbAlc}$ level in both groups.

In the present study, there was observed a significant improvement in the level of pain felt and the strength of the experimental group participants after one month of following the combined training program. This improvement was consistently observed all through the four months of the study. These findings are compatible with those obtained by Clouding et at (2012) who reported that a combined resistance-aerobic program of 10 weeks had a positive impact on the level of pain and neuropathic symptoms (measured by Michigan Questionnaire) of patients with diabetic neuropathy [11]. Moreover, these findings are line with those observed by Almeida et al. (2015) who observed that following a long regular swim exercise did indeed result in complete improvement of mechanical Allodynia and temperature Hyperalgesia in rats with neuropathic pain [25].

The neuropathic pain can be negligibly lowered by taking medications advised and prescribed by IASP (international association for the study of pain). However, these medications are not so effective in easing the pain, and are also associated with deleterious side effects. The developments in neural mechanisms of pain indicate that the longlasting (long term) plasticity changes in the pain pathways in the spinal cord and the brain are responsible for neuropathic pain [35]. These theories suggest that neural injuries or neural disorders induce glial cells activation, thus increasing the concentration of a number of mediators such as NO, glutamate prostaglandins, material P, and ATP in the space surrounding the neurons in the spinal cord and the brain which create long lasting changes in the synoptic activity of the neurons along the pain pathways, thus resulting in chronic and acute neuropathic pain sensation [36].

Stagg et al. (2011) showed that regular physical activity is associated with antinociceptive effects, concluding that regular aerobic exercises can be effective in reducing neuropathic pain through increasing the expression of brain opioid level [37]. The results of previous studies suggest that the endogenous opioid on the brain stem need to increase so that physical activities can have a lowering effect on neuropathic pain felt $[38,39]$. Although the endogenous opioid level was not analyzed in the present study, it may be inferred that the possible increase in the level of endogenous opioid induced by physical activity was responsible for the meaningful improvement of the neuropathic pain felt by the participants.

Moreover, the results of previous studies indicate that an increase in the glucose level in the blood induces toxic effects on the peripheral nervous system, thus causing acute neuropathic pain [40]. The over production of sorbitol induced by diabetes produces osmotic stress inside the cell (intracellular osmotic stress), which distorts the balance in the movement of ions through the cell membrane. This triggers the depolarization of the neuron membrane, which increases the pain in diabetic patients suffering from neuropathic pain $[41,42]$. The fact that in the present study, the blood glucose level of the patients did not show any significant change after four months of combined resistanceaerobic training program suggests that there are likely to be other mechanisms other than glucose reduction which were responsible for the reduction of the level of pain felt by the participants.

On the other hand, it has been shown that type-2 diabetic patients generally suffer from muscle weakness in ankles and knees. This general muscle weakness is more closely linked with the intensity of peripheral neuropathic pain than with other metabolic variables and conditions [43]. One of the mechanisms considered important in causing type 2 diabetes and probably the general muscle weakness which accompany this disease is the lack of sufficient physical activity. Moreover, a number of other factors have been proposed to be relevant in muscle weakness experienced by type two diabetic patient including the abnormal functioning of mitochondria, the metabolic disorders of free fatty acids, and deficiency in energy production while doing physical activities. Lowered muscle strength is usually a delayed side effect in diabetic neuropathy which is usually observed and experienced at advanced stages of the disease [44].

Magnetic resonance pictures show that the size of internal muscles of the leg in diabetic patients with neuropathy is half as large as those of healthy individuals and diabetic patients without neuropathy. Therefore, this atrophy in muscles can be directly related to the neuropathic pain these patients feel and the resulting disorders in movement functions of these individuals [45]. The general muscle weakness of the foot and leg that accompanies diabetic neuropathy increase the risk of lesions on the foot sole, thus making changes in the normal turns of leg and foot while one is walking, which results in an event distribution of load on the foot [46].

Weak muscles are more likely to reduce in size, triggering a reduction in the amount of glucose consumed which can result in hyperglycemia. Hyperglycemia, in turn, can have an adverse effect on the contraction function of the muscle, and the production of energy by the muscle. Moreover, the reduction in muscle mass results in changes in the biomechanical parts of the foot. These changes along with lowered sensation, skin dryness, callous, and limitations in joint movement can increase the pressure on the foot, increasing the risk of neuropathic lesions [47]. Therefore, it can be concluded that the reduction of the size of the muscle mass, and of the muscle strength can be considered the primary factors causing acute pain and disability in patients with diabetic neuropathy. In the present study, the significant improvement in the level of pain felt by the patients during the time they had physical training is partly due to the improvement in the strength of their muscles produced through regular physical activities they did. The improvement in muscle strength, and the significant lowering of the pain level were observed during the second month of the study.

Another relevant potential mechanism is the increase in inflammatory cytokines produced in diabetic patients. Neuropathic pain stimulates inflammatory responses, and triggers an overexpression of inflammatory cytokines in local macrophages stimulated, Schwann cells and glial cells $[48,49]$. The changes triggered in the synoptic activities of neurons along the pain pathways produce 
Citation: Parsa TA, Hosseini SRA, Bije N, Nia MRH (2018) The Study of the Effect of a 16-Week Program of Resistance-Aerobic Training on BDNF, Hba1c, Pain, and Michigan Neuropathy Score Among Type 2 Diabetic Patients with Peripheral Neuropathy. J Diabetes Metab 9: 811. doi:10.4172/2155-6156.1000811

Page 7 of 8

neuropathic pain symptoms [36]. In addition, the increase in cytokines such as TNF and IL6 has deleterious effects on the muscle mass, strength, and physical functioning of elderly patients with diabetes. In the present study, the inflammatory cytokine level was not measured. However, the observed improvements in the level of pain felt, and in the muscle strength can be partially explained by the antiinflammatory effects of the regular physical activities performed by the participants.

In sum, the results obtained in the present study indicated that the resistance-aerobic exercises performed by the subjects in the experimental group led to a statistically meaningful reduction in the average score of the subjects on the clinical part and oral part of the Michigan questionnaire, which is widely used by the specialist to identify peripheral diabetic neuropathy. The clinical examination of the questionnaire gather data on the appearance and form of the foot skin, dryness, callous, infection, deformities, the presence of lesions, Achilles tandem reflex, touch sensation, and pressure sensation while the oral interview section evaluates foot sense, pain sensation, numbness, and sensitivity to temperature. The observed improvement in the average scores on the clinical examination and the oral interview subparts of the Michigan questionnaire by the subjects in the experimental group shows that the combined program of aerobic and resistance exercises can be influential in reducing the neuropathic pain felt by patient suffering from peripheral neuropathy.

\section{Conclusion}

The obtained results in the present study generally suggest that the serum BDNF level of the patients did not show any statistically meaningful changes. However, considering the fact that the level of pain felt, and the strength of the patients as measured by the Michigan questionnaire showed a significant improvement, while the glucose and HbAlc levels did not show any significant increase, there is hope that the performance of regular physical activities for longer periods of time could be effective in improving the major indexes of disease and also in preventing these indexes and BDNF level from worsening and decreasing, respectively.

\section{References}

1. Boulton A (2005) Management of diabetic peripheral neuropathy. Clinical Diabetes 23: 9-15.

2. Meyer RA, Ringkamp M (2008) A role for uninjured afferents in neuropathic pain. Sheng Li Xue Bao 60: 605-609.

3. Saarto T, Wiffen PJ (2005) Antidepressants for neuropathic pain. Cochrane Database Syst Rev CD005454.

4. Nizard J, Lefaucheur JP, Helbert M, de Chauvigny E, Nguyen JP (2012) Noninvasive stimulation therapies for the treatment of refractory pain. Discov Med 14: 21-31.

5. Teixeira-Lemos E, Nunes S, Teixeira F, Reis F (2011) Regular physical exercise training assists in preventing type 2 diabetes development: focuson its antioxidant and anti-inflammatory properties. Cardiovasc Diabetol 10: 12.

6. Shankarappa SA, Piedras-Rentería ES, Stubbs EB Jr (2011) Forcedexercise delays neuropathic pain in experimental diabetes: effects on voltageactivated calcium channels. J Neurochem 118: 224-236.

7. Sigal, RJ, Kenny, GP, Wasserman DH, Castaneda-Sceppa C, White RD (2006) Physical activity/exercise and type 2 diabetes: a consensus statement from the American Diabetes Association. Diabetes Care 29: 1433-1438.
8. Loprinzi PD, Hager KK, Ramulu PY (2014) Physical activity, glycemic control, and diabetic peripheral neuropathy: A national sample. J Diabetes Complications 28: 17-21.

9. Krabbe KS, Nielsen AR, Krogh-Madsen R, Plomgaard P, Rasmussen P, et al. (2007) Brain-derived neurotrophic factor (BDNF) and type 2 diabetes. Diabetologia 50: 431-438.

10. Stranahan AM, Lee K, Martin B, Maudsley S, Golden E, et al. (2009) Voluntary exercise and caloric restriction enhance hippocampal dendritic spine density and BDNF levels in diabetic mice. Hippocampus 19: 951-961.

11. Kluding PM, Pasnoor M, Singh R, Jernigan S, Farmer K, et al. (2012) The effect of exercise on neuropathic symptoms, nerve function, and cutaneous innervation in people with diabetic peripheral neuropathy. J Diabetes Complications 26: 424-429.

12. Swift DL, Johannsen NM, Myers VH, Earnest CP, Smits JA, et al. (2012) The effect of exercise training modality on serum brain derived neurotrophic factor levels in individuals with type 2 diabetes. PLoS One 7: e42785.

13. Tokmakidis SP, Zois CE, Volaklis KA, Kotsa K, Touvra AM (2004) The effects of a combined strength and aerobic exercise program on glucose control and insulin action in women with type 2 diabetes. Eur J Appl Physiol 92: 437-442.

14. Dixit S, Maiya AG, Shastry BA (2014) Effect of aerobic exercise on peripheral nerve functions of population with diabetic peripheral neuropathy in type 2 diabetes: a single blind, parallel group randomized controlled trial. J Diabetes Complications 28: 332-339.

15. Hamedinia MR, Amiri-Parsa T, Khademosharie M, Azarnive1 MS, Hedayati M (2012) The effect of five-week daily aerobic exercise training and ten-week every other day aerobic training on some markers of women with type 2 diabetes. Daneshvar (medicine) shahed University 19.

16. Chen YW, Chen SH, Chou W, Lo YM, Hung CH, et al. (2007) Exercise pretraining protects against cerebral ischaemia induced by heat stroke in rats. Br J Sports Med 41: 597- 602.

17. Fouladvand M, Gharakhanlou R, Hemmat Far A. Rahmati M (2013) Adjustment of SYD gene expression in sensory neurons of diabetic neuropathic rats following endurance training. Iranian Journal of Diabetes and Metabolism 12: 292-301.

18. Feldman EL, Stevens MJ, Thomas PK, Brown MB, Canal N, et al. (1994) A practical two step quantitative clinical and electrophysiological assessment for the diagnosis and staging of diabetic neuropathy. Diabetes Care 17: 1281-1289.

19. Leutholtz, Ignacio Ripoll Boca Raton (FL) (2011) Exercise and Disease Management, 2nd ed. Brian C. CRC Press, Taylor \& Francis Group.

20. Fallahmohammadi Z, Nazari H (2014) The Effects of 4 Weeks Plyometric Training on Serum Brain Derived Nerotrophic Factor Concentration in Active Men. Journal of Sport Physiology 5: 29-38

21. Yarrow JF, White LJ, McCoy SC, Borst SE (2010) Training augments resistance exercise induced elevation of circulating brain derived neurotrophic factor (BDNF). Neurosci Lett 479: 161-165.

22. Castellano V, White L (2008) Serum brain-derived neurotrophic factor response to aerobic exercise in multiple sclerosis. J NeurolSci 269: 85-91.

23. Schiffer T, Schulte S, Hollmann W, Bloch W, Strüder HK (2009) Effects of strength and endurance training on brain-derived neurotrophic factor and insulin-like growth factor 1 in humans. HormMetab Res 41: 250-254.

24. Hvid LG, Nielsen MKF, Simonsen C, Andersen M, Caserotti P (2017) Brain-derived neurotrophic factor (BDNF) serum basal levels is not affected by power training in mobility-limited older adults-a randomized controlled trial. Exp Gerontol 93: 29-35.

25. Forti LN, Njemini R, Beyer I, Eelbode E, Meeusen R, et al. (2014) Strength training reduces circulating interleukin- 6 but not brain-derived neurotrophic factor in community-dwelling elderly individuals. Age (Dordr) 36: 9704.

26. Kim HJ, Song BK, So B, Lee O, Song W, et al. (2014) Increase of circulating BDNF levels and its relation to improvement of physical fitness following 12 weeks of combined exercise in chronic patients with schizophrenia: a pilot study. Psychiatry Res 220: 792-796. 
Citation: Parsa TA, Hosseini SRA, Bije N, Nia MRH (2018) The Study of the Effect of a 16-Week Program of Resistance-Aerobic Training on BDNF, Hba1c, Pain, and Michigan Neuropathy Score Among Type 2 Diabetic Patients with Peripheral Neuropathy. J Diabetes Metab 9: 811. doi:10.4172/2155-6156.1000811

Page 8 of 8

27. Coelhoa FM, Pereira DS ,LustosaLP, Silva JP , Dias JMD, et al. (2012) Physical therapy intervention (PTI) increases plasma brain-derived neurotrophic factor (BDNF) levels in non-trail and pre-trail elderly women. Arch Gerontol Geriatr 54: 415-420.

28. Almeida C, DeMaman A, Kusuda R, Cadetti F, Ravanelli MI, et al. (2015) Exercise therapy normalizes BDNF upregulation and glial hyperactivity in a mouse model of neuropathic pain. Pain 156: 504-513.

29. Correia PR, Pansani A, Machado F, Andrade M, Silva AC, et al. (2010) Acute strength exercise and the involvement of small or large muscle mass on plasma brain-derived neurotrophic factor levels. Clinics (Sao Paulo) 65: 1123-1126.

30. Schulz KH, Gold SM, Witte J, Bartsch K, Lang UE, et al. (2004) Impact of aerobic training on immune-endocrine parameters, neurotrophic factors, quality of life and coordinative function in multiple sclerosis. J NeurolSci 225: 11-18.

31. Knaepen K, Goekint M, Heyman EM, Meeusen R (2010) Neuroplasticityexercise-induced response of peripheral brain-derived neurotrophic factor: a systematic review of experimental studies in human subjects. Sports Med 40: 765-801.

32. Eves ND, Plotnikoff RC (2006) Resistance training and type 2 diabetes: Considerations for implementation at the population level. Diabetes Care 29: 1933-1941.

33. Arora E, Shenoy S, Sandhu JS (2009) Effects of resistance training on metabolic profi le of adults with type 2 diabetes. Indian J Med Res 129: 515-519.

34. Davis WA, Norman PE, Bruce DG, Davis TM (2006) Predictors, consequences and costs of diabetes-related lower extremity amputation complicating type 2 diabetes: The Fremantle Diabetes Study. Diabetologia 49: 2634-2641.

35. Zhuo M, Wu G, Wu LJ (2011) Neuronal and microglial mechanisms of neuropathic pain. Mol Brain 4: 31 .

36. Tawfik VL (2006) The role of glia in neuropathic pain: A journey into the tetrapartite synapse. Dartmouth College

37. Stagg NJ, Mata HP, Ibrahim MM, Henriksen EJ, Porreca F, et al. (2011) Regular Exercise Reverses Sensory Hypersensitivity in a Rat Neuropathic Pain Model Role of Endogenous Opioids. Anesthesiology 114: 940-948.

38. Hargreaves K, Dubner R, Brown F, Flores C, Joris J (1988) A new and sensitive method for measuring thermal nociception in cutaneous hyperalgesia. Pain 32: 77- 88.
39. Bian D, Nichols ML, Ossipov MH, Lai J, Porreca F (1995) Characterization of the antiallodynic efficacy of morphine in a model of neuropathic pain in rats. Neuroreport 6: 1981-1984.

40. Dobretsov M, Hastings SL, Stimers JR, Zhang JM (2001) Mechanical hyperalgesia in rats with chronic perfusion of lumbar dorsal root ganglion with hyperglycemic solution. J Neurosci Methods 110: 9-15.

41. Gomez-Cabrera MC, Domenech E, Viña J (2008) Moderate exercise is an antioxidant: upregulation of antioxidant genes by training. Free Radic Biol Med 44: 126-31.

42. Geisser ME, Wang W, Smuck M, Koch LG, Britton SL, et al. (2008) Nociception before and after exercise in rats bred for high and low aerobic capacity. Neuroscience letters 443: 37-40.

43. Andersen H, Nielsen S, Mogensen CE, Jakobsen J (2004) Muscle Strength in Type 2 Diabetes. Diabetes 53: 1543-1548.

44. IJzerman TH, Schaper NC, Melai T, Meijer K, Willems PJ, et al. (2012) Lower extremity muscle strength is reduced in people with type 2 diabetes, with and without polyneuropathy, and is associated with impaired mobility and reduced quality of life. Diabetes Res Clin Pract 95: 345-351.

45. Andreassen CS, Jakobsen J, Andersen H (2006) Muscle weakness: a progressive late complication in diabetic distal symmetric polyneuropathy. Diabetes 55: 806-812.

46. Bus SA, Maas M, Michels RP, Levi M (2009) Role of intrinsic muscle atrophy in the etiology of claw toe deformity in diabetic neuropathy may not be as straightforward as widely believed. Diabetes Care. 32: 1063-1067.

47. Boulton AJ (2004) The diabetic foot: from art to science. The 18th Camillo Golgi lecture. Diabetologia 47: 1343-1353.

48. Inoue $\mathrm{K}$ (2006) The function of microglia through purinergic receptors: neuropathic pain and cytokine release. Pharmacol Ther 109: 210-26.

49. Ledeboer A, Sloane EM, Milligan ED, Frank MG, Mahony JH, et al (2005) Minocycline attenuates mechanical allodynia and proinflammatory cytokine expression in rat models of pain facilitation. Pain 115:71-83. 